\title{
Study on Information Services and Development Approaches on Teaching and Research University Library
}

\author{
Guishan Zhang ${ }^{1, \text { a }}$ \\ ${ }^{1}$ Jilin Agricultural University, Changchun, Jilin, 130118 \\ a email
}

Keywords: Teaching and Research University; Library, Information Service Mode

\begin{abstract}
Elaborated teaching and research university library personalized information services meaning and characteristics, combined with the teaching and research university library personalized information services to carry out the situation, summarized the personalized information service four main modes. It is proposed to promote domestic teaching and research university library personalized Information Service recommendations from the body, resources, systems and technology in four areas.
\end{abstract}

\section{Introduction}

Development of teaching and research university represents the level of development of a country's higher education, their school library as one of the three pillars representing the same level of development of a national library and information. At present, our teaching and research university library has been in a period of transition from a traditional library to digital library, its services are also way from "face to face" information services, "one to one" (ie personalized) Information Services direction of change, this personalized information and services is changing the way the library in the past, "I offer what users accept anything," creating a "what you need, I'll provide any" path of development,

It will eventually become a teaching teaching and research university library's main service.

\section{The Personalized Information and Services Overview}

So far, digital library of personalized information services, although there is no uniform definition, but share a common view that this personalized information service enables the user to customize the resources they need according to their needs, information and services Meanwhile, the digital library for the user's personality and characteristics, actively select and deliver dynamic information to the user. Mainly includes the following layers of meaning: First, it is based on user needs as the center, to meet the individual needs of an information service. Second, it is a response to user needs, provide users with an information service on its own initiative. Third, it is through customized information, push technology and other means to satisfy a dynamic information service user needs.

Personalized information service is required users to customize their services to the library according to their needs, in accordance with a special library service needs of users of this offer, this service can continue to be a two-way between the user and the Library communication and feedback, until the user satisfaction.

Personalized Information Service library is based on the specific needs of users, providing personalized interface settings, personalized information environment, personalized information and personalized newsletter and other personal collections, such services are tailor-made, personalized .

Personalized information service is a library for the user's personality, interests, hobbies and characteristics of a dynamic initiative to provide users with timely updates and accurate information services. We know that in today's era of information resources is growing at an exponential rate, if the information is not timely updates, service and traditional service provided by that way there would be no essential differences.

Personalized information and services through a special system to achieve, the system provides users with information had been processed, the user security management to ensure that legitimate 
users get the appropriate customization and personalized service, improve safety.

User-level libraries face uneven, the demand for information is also diverse library of personalized information and services using intelligent system intelligent processing technology, users only need to open an individual account in the library, make their own needs the system will provide the required information or resources, greatly facilitate the users.

\section{The Teaching and Research University Library Personalized Information Service Model}

Mode is divided into the following four categories:

Personalized information and services, and is the library of the targeted groups and individuals personalized custom personalized information services, is based on the diversity of users, personalized information needs, identify the user needs to press to select, design and provide specialized information services or information products, and expand the purpose of the corresponding services. In this customization system, the system can automatically provide the user according to the needs of the services provided, the user can set their own system login interface for system operation, the collection and use of resources in the interface system; users can also set their own services, such as free choice of services, service time, the scope of services, service depth; users can also set their own search methods, such as choosing their own literature search, or ask the counselor retrieval. Currently teaching and research university libraries, custom personalized information service system is the most commonly used is MyLibrary, mobile phone library or mobile library.

Personalized information service push model is the use of push technology, professional users based on interest, subject areas, information resources, active search, and the search results and content processing and finishing, proactively pushed to the user interface. This personalized information service model key is to identify the user's points of interest, at the same time establish a correspondence between the user regularly pushed out the latest information resources. Depending on the recommended methods, it can be divided into SDI information push, push usage mining hotspot information push and push customized information, usually push email and web thematic push to complete.

Personalized Information Processing model is the use of information technology for user questions and doubts, and all kinds of information collection, collation, processing, analysis, transmission, end-users to solve various problems of information service mode. This personalized information service model is to break the traditional concept of service, the use of advanced computer and information technology, to provide users with a more convenient, more aging, more interactive information services, common modes are: Frequently Asked Questions, online consulting, BBS Consulting, subject librarian consultation, expert consultation.

Personalized Information Retrieval mode users according to their specific needs, in the library to search specific network to efficiently obtain the required information resources. Features such personalized information service model is to extract the user can demand information matches, the search results personalized output, such as automatic response, can also provide guidance and support for users of intelligent information retrieval process. Common modes are: SDI literature search, Novelty, check lead the investigation, on behalf of the check on behalf of the subject and so on.

\section{The Teaching and Research University Library Personalized Information Service Development Strategy}

In the teaching of Chinese and foreign teaching and research university library personalized information services survey, I found that they are almost similar in personalized information services and functions, contain personalized custom, information push, information consulting and information retrieval services mode. However, the starting time of their personalized information services undertaken Search Portal, reference and other differences in the United States adopt a unified OPAC retrieval entry, the domestic use of the museum design their own "personalized 
intelligent search" portal; United States to use more professional "subject Librarian" to answer the user's advice, the country is not doing such a request. From these differences, we can easily analyze results, our teaching and research university library has the following main problems in the personalized information service: a single service object, basically only serve the university's faculty; the lack of specific disciplines and services no culture appropriate subject librarian; unreasonable resource utilization, the museum fragmented, blindly demand perfection; push information is not "dig deep", to focus only on information gathering, transmission, and the lack of information on secondary finishing, processing.

For the domestic teaching and research university library personalized information service problems combined experience personalized information services libraries abroad, I believe can contribute to its development from the following aspects:

Personalized Information Service in the most significant feature is the personalized, embodied in different individuals, the object whose core is the people --- and services are all types of users, providing services to users at different levels of library staff. Therefore, personalized information service to a new height, should first highlight the "Man".

It contains two meanings: First, the user needs as the starting point, a "user-centric" service concept. Libraries should establish communication channels to communicate with users of long-term, for collecting research user's personality, interests, characteristics and needs, and the user's information service use and feedback to make timely statistics and analysis, and so designed that the user expectations personalized information service model, the initiative to provide special services to meet the needs of users, enabling the user's current and long-term potential information needs. Second, the service in the university's staff and students as the basic point, the progressive realization of social service objects. As we all know, social groups and school readers compared the habits vary widely, the wider interest, the demand for all-inclusive, which is carrying out this work for the library put forward higher requirements, but also provide a broader stage. If society of personalized information services can be resolved, it will undoubtedly personalized information service level of library produces a qualitative leap.

The most obvious difference between teaching and research university is different from ordinary universities' scientific research ability, to match the corresponding university, teaching and research university established the first library Subject Librarian System. The so-called "Subject Librarian" refers to a library designated persons and certain faculties or disciplines as counterparts to establish contact between departments, disciplines and library a bridge, communicate with each other, the user actively targeted of the collection, provision of documentation information services. Therefore, subject librarian personalized information service is the most important service, and his level of service determines the level of library services for the construction of discipline, while also reflecting the extent of mining information push. This requires discipline librarians not only have solid information service ability, but also the times of professional standards and discipline information technology capabilities.

Personalized Information Service Another important element is the information service, which reflects offers unique information in the library, how to provide convenient services. On the one hand, the nature of the information is all kinds of resources, teaching teaching and research university libraries should be based on its own resources collection features and characteristics of school discipline, the establishment of a database with local characteristics or school characteristics; at the same time, timely collected network resources, targeted to provide users with "dig deep" information. On the other hand, saving the user from obtaining time information, enhanced service initiative, to update and adjust service information system by analyzing the user's interest, automatically provides users with a recommended starting pages and links, the establishment of specialized portals site service, to provide users with more convenient services.

Regulatory regimes-establish a unified national bibliographic cataloging data center interviews and teaching Teaching \& Research University Library Although there is a rich collection of resources, but it is difficult to rely solely on their own resources to meet the growing demand for personalized information, so should the overall situation, and gradually establish this area, the 
system even national bibliographic interview center for all kinds of resources, especially digital resource unified ordering, unified distribution, sharing of resources, so that not only meets the needs of users personalized information, but also saves the state's investment, but also improve the utilization of resources. In addition, it should also establish appropriate cataloging data center, our country because there is no corresponding "Library Act" do support, so there is no established national library administration, it has not the resources to establish a unified search interface, which reduces the intangible resources the full-rate detection and inspection precision, providing personalized information service set up obstacles for the library.

Teaching and research university library personalized information service is a web-based environment, its implementation depends on computers, information, intelligence technology do support. Customization services that depend on library automation systems integration; integrated client service system relies on the knowledge management system; Distributed Reference Service relies on cloud computing technology; user privacy and intellectual property protection relies on network information security technology ....... With data mining, intelligent information processing technology, the development of artificial intelligence, intelligent algorithms and technology for digital library construction and personalized information services to provide strong technical support. With the rapid development of geometric growth of information technology and network of various resources, teaching teaching and research university libraries will face new challenges and opportunities, and personalized information services will also be leading the future of University Library Information Service. Therefore, the meaning and essence of teaching research university libraries from personalized information and services to understand the information services, and actively explore and fully exploit the various resources, learn from foreign experience personalized service, really pushing the Library Personalized Information Service development of.

\section{References}

[1] Li Shangmin. Comparative Study of Library Information Service and Knowledge Service [J]. Modern intelligence, 2007, (12): 33-37.

[2] Tan Rong. Big Data University Library Information Service Innovation [J]. New Media Research, 2015, (13): 57-59.

[3] Liu Yanmei. Personalized Information Service under the Network Environment measures discussed [J]. Science and Technology Information, 2015, (12): 175-177.

[4] Zhang Shujun. The subject librarian and subject service [J]. Hunan University of Science and Technology, 2015, (12): 203-204. 